\title{
A JUSTIÇA AMBIENTAL COMO INSTRUMENTO NO COMBATE A DISTRIBUIÇÃO DESIGUAL DO RISCO ECOLÓGICO EM SOCIEDADES DITAS PERIFÉRICAS
}

\author{
Luís Marcelo Mendes ${ }^{1}$ \\ Jerônimo Siqueira Tybusch ${ }^{2}$
}

\begin{abstract}
Resumo: O artigo analisa a atuação da justiça ambiental como mecanismo de luta contra a distribuição desigual do risco ecológico no intuito de assegurar o acesso ao meio ambiente sadio e equilibrado. A pesquisa se utiliza do método dedutivo assessorada por premissas dialéticas para vislumbrar um diagnóstico sobre a problemática. Em um primeiro, momento analisar-seá a precarização da condição humana e seus desdobramentos na distribuição desigual do risco ecológico e na proliferação da injustiça ambiental. Posteriormente, verificar-se-á a atuação da justiça ambiental como instrumento de luta contra a geopolítica da propagação da desigualdade ecológica em sociedades ditas periféricas.
\end{abstract}

Palavras-chave: Justiça ambiental. Risco ecológico. Desigualdade ecológica.

\section{ENVIRONMENTAL JUSTICE AS AN INSTRUMENT IN COMBATING THE UNEQUAL DISTRIBUTION OF ECOLOGICAL RISK IN SOCIETIES PERIPHERALS}

\begin{abstract}
The article analyzes the performance of environmental justice as a mechanism to combat the unequal distribution of ecological risk in order to ensure access to a healthy and balanced environment. The research uses the deductive method advised by dialectical premises to envisage a diagnosis about the problem. In a first, moment will analyze the precariousness of the human condition and its unfolding in the unequal distribution of ecological risk and in the proliferation of environmental injustice. Subsequently, the performance of environmental justice as an instrument of struggle against the geopolitics of the propagation of ecological inequality in peripheral societies will be verified.
\end{abstract}

\footnotetext{
${ }^{1}$ Mestre em Direito pela Universidade Federal de Santa Maria (UFSM -2015). Especialista em Direito Constitucional Contemporâneo pela Universidade de Passo Fundo (UPF - 2010). Bacharel em Direito pela Universidade Luterana do Brasil (ULBRA - 2007). Integrante do Grupo de Pesquisa em Direito da Sociobiodiversidade (GPDS), inscrito no CNPq, com atuação na Linha de Pesquisa: Ecologia Política e Direito da Universidade Federal de Santa Maria (UFSM).

${ }^{2}$ Doutor em Ciências Humanas pela Universidade Federal de Santa Catarina - UFSC (2011); mestre em Direito Público pela Universidade do Vale do Rio dos Sinos - UNISINOS (2007); graduado em Direito pela Universidade de Santa Cruz do Sul - UNISC (2004). Professor Adjunto no Departamento de Direito da Universidade Federal de Santa Maria - UFSM. Professor do Programa de Pós-Graduação em Direito (PPGD/UFSM) - Mestrado em Direito. Professor do Programa de Pós-Graduação em Tecnologias Educacionais em Rede (PPGTER/UFSM) - Mestrado Profissional em Tecnologias Educacionais em Rede. Pesquisador e ViceLíder do Grupo de Pesquisa em Direito da Sociobiodiversidade - GPDS. Atualmente é Coordenador de Planejamento Acadêmico da Pró-Reitoria de Graduação da UFSM.
} 
Keywords: Environmental justice. Ecological risk. Ecological inequality.

\section{INTRODUÇÃO}

$\mathrm{O}$ artigo visa evidenciar a atuação da justiça ambiental como estrutura essencial no combate a distribuição desigual do risco ecológico em sociedades ditas periféricas. A elaboração deste arquétipo jurídico tem o intuito de garantir o acesso ao meio ambiente sadio e equilibrado para todos os indivíduos. Nesse ínterim, é necessário um modelo de justiça que possa materializar esse direito a partir de um diagnóstico sob a complexidade da problemática ecológica contemporânea. Esse modelo deve possuir a premissa de efetivar a criação de mecanismos capazes de refrear/suprimir a propagação dos riscos ecológicos. Sob esse prisma, é preciso uma nova acepção de justiça ambiental com capacidade de combater o processo de propagação geopolítica da distribuição desigual do risco ecológico em sociedades ditas periféricas.

Frente a esta conjectura, a pesquisa utilizar-se-á do aporte do método dedutivo com o objetivo concretizar uma análise de maior amplitude sobre o papel da justiça ambiental como mecanismo refreador/supressor da distribuição desigual do risco ecológico em sociedades ditas periféricas. Por meio da verificação do contexto factual através de aporte teórico e bibliográfico atualizado. A respectiva pesquisa far-se-á uso da dialética a fim de realizar o embate dos questionamentos averiguados, no intuito de delinear possíveis soluções para a problemática ventilada.

Em um primeiro momento, procurar-se-á demonstrar como se desenrola o fenômeno de precarização da condição humana e seus consequentes desdobramentos na distribuição desigual do risco ecológico. Os inúmeros fenômenos sociais/complexos advindos da modernidade contribuem para a alteração da condição humana em escala global. O risco se instaura como parte desta condição, como ênfase, o risco ecológico. Sob esse contexto, surge a proliferação da injustiça ambiental, haja vista, que a justiça/direito não consegue fazer frente à produção/distribuição desigual do risco ecológico em sociedades ditas periféricas.

Posteriormente, analisar-se-á de forma mais acurada como se desenvolve o processo de alastramento da injustiça ambiental em sociedades ditas periféricas. É possível perceber que a injustiça ambiental está correlacionada com a transformação da percepção sobre economia/técnica-ciência/déficit democrático. Para tanto, abordar-se-á o surgimento do movimento ambientalista contemporâneo, que será responsável pelo processo de gestação de 
um modelo de justiça ambiental. A construção desse modelo jurídico está comprometida com o combate à desigualdade econômica e suas reverberações no sentido de refrear/suprimir a distribuição desigual do risco ecológico.

A justiça configura como mecanismo essencial para a estrutura de uma ordem social. Sob esse contexto, a justiça deve criar mecanismos para afiançar uma existência digna para todos os indivíduos através da construção de mecanismos jurídicos que assegurem a concretização de direitos e/ou garantias fundamentais. Frente essa conjectura, está em processo de estruturação de um novo modelo de justiça ambiental capaz de refrear/suprimir a distribuição desigual do risco ecológico. Este novo modelo de justiça ambiental tem sua gestação dentro do movimento ambiental contemporâneo.

Por fim, delinear-se-á que à consolidação de um novo modelo de justiça ambiental capaz de refrear/suprimir a distribuição desigual do risco ecológico, precisa estar vinculado ao combate à desigualdade social de caráter econômico. É necessário delinear que os problemas ecológicos contemporâneos estão conectados aos indivíduos em situação de vulnerabilidade econômica. Assim, se torna perceptível a necessidade da criação de uma estrutura democrática que permita a participação de todos os indivíduos, em todas as etapas do processo decisório referente ao acesso/manutenção dos recursos naturais dos seus respectivos territórios.

\section{A PRECARIZAÇÃO DA CONDIÇÃO HUMANA E SEUS DESDOBRAMENTOS NA DISTRIBUIÇÃO DESIGUAL DO RISCO ECOLÓGICO: um diagnóstico sobre a proliferação da injustiça ambiental na contemporaneidade}

$\mathrm{O}$ acesso ao meio ambiente ecologicamente equilibrado figura como um direito universal/fundamental inerente a todo o ser humano como forma de materializar o preceito da dignidade da pessoa humana. A degradação ecológica na contemporaneidade assume contornos globais, onde o processo de globalização da economia, da revolução informacional e o déficit democrático impulsionados pela ação do mercado deflagram a instauração de uma sociedade de risco. O risco ambiental passa a ser distribuído de forma desigual ${ }^{3}$ entre os indivíduos, com

\footnotetext{
${ }^{3} \mathrm{O}$ processo de distribuição da "desigualdade ambiental pode manifestar-se tanto sob a forma de proteção ambiental desigual como de acesso desigual aos recursos ambientais. A proteção ambiental é desigual quando a implementação de políticas ambientais - ou a omissão de tais políticas ante a ação das forças do mercado - gera riscos ambientais desproporcionais, intencionais ou não intencionais, para os mais carentes de recursos financeiros e políticos: os mais pobres, os moradores de áreas desvalorizadas e etnias marginalizadas" (ACSELRAD, MELLO, BEZERRA, 2009, p. 73).
} 
ênfase, nos indivíduos em situação de vulnerabilidade aglutinados em sociedades ditas periféricas.

A sociedade moderna é fustigada por uma pluralidade/complexidade inerentes dos processos sociais decorrentes da ação da globalização, visto que a globalização não se configura como "um processo singular, mas um conjunto complexo de processos. E estes operam de uma maneira contraditória ou antagônica" (GIDDENS, 2007, p. 23). A sociedade de risco emerge nesse contexto, fruto das transformações advindas dos fenômenos da globalização. O risco passar a fazer parte da condição humana de forma irremediável.

A distribuição do risco na modernidade altera a percepção dos indivíduos sobre realidade que os cerca, através da modificação de conceitos como economia, ciência e política com desdobramentos diretos no acirramento do risco de colapso ecológico global. Já que o risco é propagado sob um prisma "democrático" vinculado as incertezas transtemporais. O alastramento do risco atinge todos os indivíduos em escala global, mas frente a sua lógica distributiva economicista tende a gerar seus primeiros impactos junto aos indivíduos em situação de vulnerabilidade econômica em sociedades ditas periféricas (BECK, 2011).

A distribuição desigual do risco ambiental entre os indivíduos afeta de forma mais contundente os extratos sociais dos grupos historicamente vulnerabilizados, dentre os quais estão inclusos: as populações negras, os indígenas, os pobres e os trabalhadores. A repartição desigual do risco ecológico aumenta exponencialmente as condições de precarização da vida dos integrantes pertencentes aos grupos historicamente vulnerabilizados. Visto que estes indivíduos não estão inclusos no padrão social hegemônico pré-determinado pela lógica economicista do capital. Sob essa conjectura, é possível constatar que existe uma considerável “diferença nos graus de exposição das populações aos males ambientais, isso não decorre de nenhuma condição natural, determinação geográfica ou causalidade histórica, mas de processos sociais e políticos que distribuem de forma desigual a proteção ambiental" (ACSELRAD, MELLO, BEZERRA, 2009, p. 73).

A divisão desigual do risco ecológico está condicionada a certos fatores que compõe a estrutura social moderna como o poder econômico dos indivíduos, visto que "a produção social da riqueza é acompanhada sistematicamente pela produção social de riscos" (BECK, 2011, p. 23). A reverberação do poder econômico afeta de forma mais contundente os indivíduos em situação de vulnerabilidade econômica, os desprovidos de acesso a políticas públicas 
afirmativas. Em suma, os que vivem na margem/abaixo da linha de pobreza, os moradores de áreas desvalorizadas e os indivíduos que pertencem a etnias historicamente marginalizadas.

A ordem econômica liberal visa implantar/consolidar uma agenda proativa vinculada com a propagação do ideário do capital, tal postura necessita de um aporte ideológico para se firmar. Essa postura exercer uma influência ideológica alienadora sobre a conduta do indivíduo com força suficiente para alterar a sua capacidade de interação social com os demais indivíduos. A edificação do arquétipo sobre os benefícios de uma consciência individual/coletiva de natureza economicista/liberal demonstra a necessidade de pontuar que "a ideologia não é ilusão nem superstição de indivíduos mal orientados, mas uma forma específica de consciência social, materialmente ancorada e sustentada" (MÉSZÁROS, 2004, p. 78).

A primazia desta consciência individual/coletiva de natureza economicista/liberal acarreta um comportamento individual/coletivo condicionado à ideologia do capital que objetiva construir/consolidar uma sociedade homogeneizada através de valores prédeterminados pela lógica do próprio capital. Nesse sentido, Adam Smith (2006), argumenta que os indivíduos decidem e escolhem num primeiro momento com base no seu interesse pessoal (egoísmo). Assim, essa acepção tem por base o sentimento de simpatia e empatia e no anseio do companheirismo que os indivíduos nutrem uns pelos outros, de tal modo que o indivíduo necessita do auxílio de seus companheiros para prosperar. Porém, não se pode esperar conseguir isso por mera benevolência, pois "não nos dirigimos ao seu espírito humanitário, mas sim ao seu amor-próprio" (SMITH, 2006, p. 25).

Adam Smith (2006) através de suas pesquisas delineia as conjecturas sociais que deflagrariam a superioridade de certos indivíduos sobre o resto dos seus semelhantes. Para atingir tal intento, o filósofo verifica as diversas nuances acerca de determinadas particularidades sociais que envolvem a problemática do processo de submissão institucional e da coerção de um pequeno contingente de indivíduos sobre uma maioria, nas inúmeras conjunturas sociais da época. A construção desta concepção ideologia alienadora "afeta tanto os que desejam negar sua existência quanto aqueles que reconhecem abertamente os interesses e os valores intrínsecos das várias ideologias" (MÉSZÁROS, 2004, p. 79).

Sob esse contexto, acontece o esboço da condição humana moderna. A condição humana, na visão arendtiana, determina às circunstâncias de vida que o homem se impõe para sobreviver. Assim, a condição humana é estipulada através do componente geográfico e pelo momento histórico no qual o indivíduo está inserido. O comportamento dos indivíduos é 
condicionado, onde até mesmo os condicionadores se tornam condicionados pelo ato de condicionar. $\mathrm{O}$ ato de condicionar se desenvolve sob duas formas distintas. A primeira forma de condicionamento está vinculada aos aspectos internos dos indivíduos onde figuram seus atos/pensamentos/sentimentos. A segunda forma estaria ligada ao contexto externo fruto de uma conjuntura histórica/cultural/familiar dos indivíduos (ARENDT, 2007).

A concepção deste cenário acaba por contribuir na formação/consolidação de uma sociedade desigual devido a sua conjectura economicista, que por sua vez propaga a desigualdade ecológica entre seus membros, pois o desenvolvimento não ocorre de maneira uniforme. Nesse sentido, é necessário ponderar que "o desenvolvimento com justiça ambiental requer a combinação de atividades no espaço e de modo a que a prosperidade de uns não provenha da expropriação dos demais" (ACSELRAD, MELLO, BEZERRA, 2009, p. 77).

A atuação do sistema financeiro global determina como se dará o acesso dos indivíduos a uma existência digna na contemporaneidade, a mesma está ligada a lógica do padrão de consumo, onde o consumo passa a figura como um aglomerado de fenômenos socioculturais com o objetivo de realizar a apropriação/uso dos produtos. Sob esse prisma, o consumo é o lugar onde ocorre a luta de classes, a propagação das desigualdades na estrutura produtiva, na apropriação e na distribuição de bens entre os indivíduos (CASTELLS, 2006).

Nesta conjectura, "a crise ambiental coloca em questão os fundamentos da racionalidade econômica" (LEFF, 2015, p. 42), já que é possível verificar a consequente simbiose entre o comportamento dos indivíduos e à lógica econômica imposta pelo ideário capitalista. As estruturas do movimento da vida contemporânea podem ser definidas pela metáfora de turistas e vagabundos desenvolvida por Bauman (1998, p. 119), ao propagar que “[...] os vagabundos são depósitos de entulho para a imundície do turista; desguarneça-se o sistema de recolhimento dos detritos e as pessoas saudáveis desse mundo são sufocadas e envenenadas no meio dos seus próprios restos."

A metáfora incutida por Bauman (1998) determina o ponto imbricação dos efeitos econômicos na produção da desigualdade ecológica entre os indivíduos detentores do poder econômico e os despossuídos. Os indivíduos detentores do poder econômico têm a capacidade de escolher as condições/mecanismo para garantir uma existência digna. Já, no outro extremo os indivíduos despossuídos que estão à margem de qualquer direito, expostos as mais diversas formas de riscos, com ênfase, nos riscos prolatados na área de saúde e meio ambiente, haja vista 
que não têm opção, pois carecem de recursos econômicos para acessar os mecanismos afiançadores de uma existência digna diante da lógica econômica.

A incorporação das novas tecnologias da informação na sociedade moderna contribui no processo de integração/conexão de um novo contexto social para os indivíduos por intermédio de redes globais de instrumentalidade, que corroboram na alteração da dinâmica social contemporânea. A revolução tecnológica impulsiona o capital, a articular novas estratégias empresariais com o intuito de aumentar a produtividade e consequentemente a lucratividade dos detentores dos meios de produção (CASTELLS, 2006).

Para atingir tal intento, se torna necessário buscar novos mercados através da internacionalização da produção. Contudo, é perceptível que “as empresas multinacionais e suas redes de produção são, ao mesmo tempo, instrumentos de domínio tecnológico e canais de difusão de tecnologia seletiva" (CASTELLS, 2006, p. 167). Frente esta lógica, o processo de acesso a informação passa a ser controlado e massificado por empresas transnacionais privadas. A atuação destes atores sociais através das suas redes de produção impõe restrições a nossa liberdade de pensamento, o acesso a informação sobre o grau de toxidade dos bens/insumos desenvolvidos, passa a ser seletiva, ou seja, essas informações não estão acessíveis a todos os indivíduos.

A atividade poluente gerada por essa nova estratégia empresarial afeta os países em desenvolvimento. A maioria destes países tem uma legislação mais branda no que se refere à produção de danos ambientais com o objetivo de atrair empresas para aumentar o desenvolvimento econômico através da criação de empregos. Essa estratégia denota a ligação do caráter econômico na propagação da degradação do natural por meio da desigualdade econômica (CASTELLS, 2006). O risco ambiental é transferido para os países periféricos com a premissa de evitar/retardar a chegada deste risco aos países hegemônicos. Os países hegemônicos figuram como desenvolvedores deste mesmo risco, por meio da construção de novos produtos frutos do uso das novas tecnologias, em especial, dos bens/insumos de origem biotecnológica.

O risco toma forma através da construção de eventos/ações no espaço-tempo futuro, ou seja, o risco se materializa através da incerteza que se produz no campo das nossas expectativas/ações, com foco, nas produzidas no campo político. O risco consiste na antecipação da catástrofe. O campo político se tornou o palco do debate onde os conflitos que provocam riscos operam, uma vez que as pautas que ocasionam os problemas ligados a 
produção do risco na sociedade contemporânea são amplamente divulgadas/debatidas numa perspectiva democrática, mas decididas a portas fechadas. O déficit democrático tem contribuído na construção desta lógica perversa (BECK, 2011).

O poder político instituído pela lógica econômica do capital não deve se opor a esse comportamento "natural" dos indivíduos, ou seja, o governo deve atuar em consonância com essa lógica economicista por meio da concepção de mecanismos políticos/jurídicos para consolidar/perpetuar essa matriz econômica hegemônica (FOUCAULT, 2008). Sob esse contexto, as demandas por justiça ambiental superam o paradigma prolatado pelo direito ambiental tradicional, pois as consequências da desigualdade econômica se irradiam e tem como efeito colateral o alastramento da desigualdade ambiental em sociedades ditas periféricas.

Sob esse prisma, o mercado faz uso da recessão econômica para legitimar políticas neoliberais, diminuído os tentáculos do Estado na esfera social, haja vista, que frente essa conjectura existe uma imbricação de fatores que auxiliam na manutenção do sistema econômico e o eventual enfraquecimento da democracia. Diante do panorama global de recessão econômica, a cartilha neoliberal propaga o aumento do desemprego acompanhado da desarticulação da população trabalhadora. Frente esse cenário, incide a arrefecimento da preocupação da categoria empresarial "com a manutenção, uma intensificação dos ritmos de trabalho dos que não perderam seus empregos, o crescimento dos acidentes de trabalho e da irresponsabilidade ambiental das empresas" (ACSELRAD, 2017, p. 02).

Do mesmo modo, o processo de democratização sob o controle dos riscos ecológicos acaba por ser desencadeado nos momentos "de menor incidência do desemprego e de maior capacidade de mobilização dos atores sindicais" (ACSELRAD, 2017, p. 02), uma vez, que nesse panorama os atores sociais acabam por exercer pressão na classe empresarial para realizarem a manutenção de um aparato com o objetivo de resguardar os recursos naturais de suas atividades comerciais, em especial, as atividades que contribuem para o aumento da poluição nas áreas mais pobres.

Nesse ínterim, é possível observar "a veloz corrosão dos direitos e do Direito suscitada pela evolução econômica de um mundo globalizado, o que salta aos olhos é a impressão de inevitabilidade desse processo" (SANTOS, 2011, p. 229). A democracia moderna sofre as sequelas da metamorfose imposta pelo capital, por meio da supressão de direitos e/ou garantias fundamentais dos indivíduos contribuindo assim no processo de aceleração da precarização da condição humana, “como se as sociedades nacionais democráticas tivessem sido precipitadas 
num momento de desarticulação por uma força tal, que nenhuma outra parece capaz de fazerlhe frente" (SANTOS, 2011, p. 229).

A justiça ambiental traz consigo a esperança de mudança na abordagem da problemática ambiental contemporânea, através do combate à desigualdade econômica por intermédio da criação de mecanismos políticos/jurídicos que assegurem um tratamento igualitário a todos os indivíduos independente de raça, etnia ou classe social, a fim de refrear/suprimir a distribuição do risco ecológico de forma desproporcional. O movimento para garantir uma nova acepção de justiça ambiental perpassa por mudanças na estrutura político/jurídica que assegurem a participação efetiva das comunidades envolvidas em todas as etapas do processo decisório acerca da utilização dos recursos naturais de seus territórios com o intuito de refrear o processo de degradação ecológica.

\section{A JUSTIÇA AMBIENTAL COMO INSTRUMENTO DE COMBATE A GEOPOLÍTICA DA PROPAGAÇÃO DESIGUAL DO RISCO ECOLÓGICO EM SOCIEDADES DITAS PERIFÉRICAS}

A geopolítica da propagação desigual do risco ecológico presta fôlego à crise ecológica que se instaura/solidifica em virtude da construção de uma conjectura econômica/técnicacientífica/déficit democrático moldada sob a ótica da lógica economicista do capital. Resta demonstrada, à incapacidade do direito ambiental tradicional em prestar aporte para transcender esse contexto ecológico catastrófico. Para tentar reverter esse prognóstico, urge a necessidade de (re)pensar a concepção de justiça, sob o prisma ambiental a fim de gerar uma mudança no atual paradigma ecológico imposto.

A justiça possui a característica de ser possível, contudo não necessária a ordem de uma sociedade, pois diante de um homem virtuoso ela passa a segundo plano, haja vista, que a conduta de um homem justo está atrelada a uma ordem produzida como justa. O comportamento dos indivíduos deve ser regulado de forma a satisfazer a todos, já que a ambição por justiça está ligada a eterna busca do indivíduo por felicidade. Assim, o homem isolado não consegue alcançá-la, e para tanto necessita buscá-la na própria sociedade, pois a "justiça é felicidade social, é a felicidade garantida por uma ordem social” (KELSEN, 2001, p. 02).

Nessa linha de pensamento uma ordem justa leva em conta a felicidade dos indivíduos. Entretanto, a "felicidade" figura como um conceito subjetivo, uma vez, que o conceito sofre variações entre os próprios indivíduos. Assim, não pode haver unanimidade em torno do conceito, pois o que faz um homem "feliz" pode causar a infelicidade do outro. Sob essa ótica, 
é impraticável perpetrar uma ordem social justa que vise assegurar a felicidade, esta ordem pode materializar a felicidade individual ou tentar assegura a felicidade ao maior número de indivíduos possível dentro de uma perspectiva utilitarista.

Deste modo, o direito tradicional por meio do princípio da igualdade articula a "felicidade" para o maior número de indivíduos possível sob um viés jurídico formal, esse modelo está atrelado ao paradigma de uma sociedade homogênea. No entanto, a globalização, em especial, a econômica alterou a interação entre os sujeitos numa escala global, e cria um novo modelo social calcado no consumo, onde o sujeito perde sua noção de identidade, haja vista, que esse fenômeno ocasionou o processo de desistoricização e dessubjetivação do sujeito contemporâneo.

Nesse ínterim, passa a ser indispensável repensar o ideário de igualdade, em especial, a igualdade jurídica no intuito de adequá-la a esse novo cenário de transformações sociais, onde ocorre à deterioração da identidade dos sujeitos. Sob essa premissa, a turbulência ocasionada pelas mudanças da ordem social moderna, impele o sujeito a buscar guarida em critérios culturais, étnicos, religiosos e políticos a fim de reencontrar/reconstruir a sua identidade enquanto sujeito.

Sob essa ótica, Jonh Rawls (2002) em sua obra Uma Teoria de Justiça, propaga uma nova acepção para justiça onde está deve estar comprometida com o preceito da equidade. A construção de um novo padrão de justiça vinculado com a equidade pode ser delineada pelas categorias de princípios da justiça, posição original e véu da ignorância. Essas categorias cunhadas por Rawls têm por premissa determinar a necessidade das ações/escolhas dos indivíduos serem norteadas por uma sensatez racional capaz de gerar desdobramentos na conduta social.

A concepção de uma sociedade que combata a desigualdade social deve ser direcionada por um modelo de justiça comprometido com a implantação de um sistema de cooperação que atenda os interesses mútuos dos indivíduos. Diante dessa conjectura, haveria a materialização de uma justiça comprometida com a equidade, pois "uma sociedade é bem-ordenada não apenas quando está planejada para promover o bem de seus membros, mas quando é também efetivamente regulada por uma concepção pública de justiça” (RAWLS, 2002, p. 05).

Frente esse cenário, Rawls (2002) apregoa a construção de um modelo de sociedade baseado na concepção de uma justiça distributiva, onde a ordem social deve ser determinada pela criação/elaboração de mecanismos jurídicos capazes de regular/compensar os indivíduos. 
Esse modelo estrutural contribuiria no processo de minimização das desigualdades econômicas, a fim de atribuir um tratamento que contemple a equidade entre os indivíduos. A formulação destes conceitos irá gerar mudanças substanciais acerca da concepção de justiça e reverbera na construção de um modelo de justiça ambiental delineado no movimento ambientalista contemporâneo.

A atuação do movimento ambientalista assume relevância a partir da década de 60 do século passado, mas apenas na década de 90 ocorrerá a consolidação do movimento ambientalista nos Estados Unidos e em alguns países da Europa. O movimento ambientalista passa a pressionar o sistema econômico no intuito de conter a degradação ecológica através de um conjunto de ações com o objetivo de alterar as agendas políticas de governos e instituições internacionais. As empresas transnacionais privadas, mesmo as grades poluidoras, incorporam o discurso de preservação ecológica com vistas a angariar mais consumidores e por consequência aumentar a sua fatia no mercado consumidor para os seus produtos/serviços "ecológicos" (CASTELLS, 2006).

O movimento ambientalista frente uma análise sociológica mais acurada não pode ser comparado aos movimentos sociais tradicionais. O movimento ambientalista possui natureza complexa, pois atua em várias esferas sociais para atingir o seu intento, e opera com mais ênfase na busca pela implantação da equidade, nos campos econômicos e político. Contudo, a atuação do movimento ambientalista não se restringe somente ao embate nessas áreas, Tybusch (2011, p. 312) determina que a luta, "abrange, todavia, possibilidades para constituição de uma nova ordem social, ou seja, de um projeto social que perpasse diferentes sistemas (econômico, político, jurídico e cultural) enquanto comunicação ecológica."

A sociedade contemporânea evolui aceleradamente, esse fenômeno deflagra inúmeros conflitos sobre a supremacia de determinados interesses devido à complexidade das relações sociais. O movimento ambientalista visa se incorporar neste novo contexto social, para aturar como ator na transformação do paradigma ecológico a partir do desenvolvimento de novos mecanismos de luta/pressão para a efetivação de uma justiça ambiental comprometida com a materialização dos direitos humanos e/ou fundamentais dos indivíduos. Para atingir tal intento elenca o combate à desigualdade social por meio da participação destes indivíduos em todas as etapas decisórias acerca da utilização dos recursos naturais de seus respectivos territórios.

O movimento ambientalista contemporâneo tem como traço marcante a pluralidade das “ações coletivas, políticas e discursos agrupados sob a égide do ambientalismo são tão 
diversificados que torna praticamente impossível considerá-lo um único movimento" (CASTELLS, 2006, p. 143). Sob esse ponto de vista, se inicia uma nova fase no debate sobre as questões/problemas ecológicas contemporâneas suscitadas pelo movimento ambientalista moderno. Assim, será delineada a construção do Movimento de Justiça Ambiental. O conceito de justiça ambiental tem por característica a aplicação de um tratamento justo por meio da inclusão equitativa dos grupos sociais afetados diretamente pelos problemas ecológicos. Nesse cenário, os grupos sociais teriam acesso a um espaço democrático para discussão sobre o uso/ocupação dos recursos naturais de seus territórios. O movimento ambiental prolatará essa nova acepção de justiça, que está balizada no combate à desigualdade social na seara econômica.

O Movimento de Justiça Ambiental nasce em 1960 nos Estados Unidos, mas se articula de forma mais contundente, em 1982, junto à comunidade de Afton, no condado Warren, no estado americano da Carolina do Norte. A mobilização por justiça ocorre após a descoberta dos moradores da localidade que a mesma fora construída sob um aterro químico, houve inúmeros protestos e manifestações de repúdio, as atividades foram reprimidas com violência, haja vista, que ocorreram mais de quinhentas prisões de manifestantes (FROTA; MEIRELES, 2008).

O U.S. General Accounting Office, em 1983, organizou uma pesquisa intitulada Siting of Hazardous Waste Landfills and Their Correlataion with Racial and Economic Status of Surrounding Communities. Os dados coletados na pesquisa apontaram que $20 \%$ da população total da área composta por comunidades afro-americanas, da região quatro, que engloba oito Estados no sudoeste dos Estados Unidos foram construídas em áreas situadas sob aterros de resíduos químicos perigosos (FROTA; MEIRELES, 2008).

O resultado da pesquisa torna evidente a nefasta imbricação entre raça, desigualdade econômica e a degradação ecológica. Deste modo, em 1987, as entidades de base das comunidades atingidas pelo problema ambiental dos aterros químicos iniciam um processo de discussão para delimitar as relações entre raça, pobreza e seus desdobramentos junto à problemática ecológica e a desigualdade social. A pesquisa possuía a premissa contribuir para a elaboração de um instrumento de "Avaliação de Equidade Ambiental”. Deste modo, a partir desse novo instrumental metodológico foi possível a inserção de uma série de variáveis sociais no estudo de avaliação sobre o impacto ambiental (ACSELRAD, 2002).

A proposta do novo instrumental teórico é viabilizar a ação participativa dos grupos sociais em situação de vulnerabilidade ecológica. O novo instrumental teórico gera a 
democratização do acesso ao conhecimento, e cria um saber comprometido com a realidade local dos sujeitos afetados por situação de risco ecológico com objetivo de buscar alternativas para a superação da problemática ambiental, por meio de ações direcionadas para modificar a sua realidade socioambiental (ACSELRAD, 2002).

Diante da perspectiva de combater a exclusão social vivenciada por esses indivíduos em situação de vulnerabilidade social/econômica/ecológica pontua-se que "a luta contra a 'exclusão' correspondem, assim, finalmente, a um tipo clássico de focalização da ação social: delimitar zonas de intervenção que podem dar lugar às atividades de reparação" (CASTEL, 2000, p. 29). Desta forma, a luta contra a exclusão social/econômica/ecológica teria o condão de alterar a realidade desses sujeitos e buscar inseri-los no rol da cidadania plena.

A I Cúpula Nacional de Lideranças Ambientalistas de Povos de Cor, ocorrida em 1991 na cidade de Washington, foi responsável pela confecção do documento intitulado os "17 princípios da justiça ambiental”, com o objetivo de combater a poluição oriunda da desigualdade ambiental provocada pela ação econômica. Os "17 princípios da justiça ambiental" conseguem uma ampla divulgação na Conferência das Nações Unidas para o Meio Ambiente e o Desenvolvimento, realizada no Rio de Janeiro, em 1992, e consolida/publiciza os preceitos ventilados pelo Movimento de Justiça Ambiental (FROTA; MEIRELES, 2008).

O Movimento de Justiça Ambiental provoca uma alteração no olhar sobre o tratamento da problemática ambiental contemporânea. Os " 17 princípios da justiça ambiental” incorporam a temática da problemática ecológica: a luta por causas de caráter social, territorial e de direitos civis por meio de uma abordagem "holística", complexa e transdisciplinar. A justiça ambiental tem a premissa de construir um direito comprometido com um "meio ambiente sadio e produtivo para todos, onde o 'meio ambiente' é considerado em sua totalidade incluído suas dimensões ecológicas, físicas construídas, sociais, políticas, estéticas e econômicas" (ACSELRAD; MELLO; BEZERRA, 2009, p. 16).

Em 1998, é criada a Rede Brasileira de Justiça Ambiental (RBJA), está se consolida em 2002 como um espaço de identificação e de fortalecimento dos princípios da Justiça Ambiental (TYBUSCH; AGNE TYBUSCH, 2015). O Movimento de Justiça Ambiental atua através de uma rede multicultural/multirracial comprometida com um modelo de justiça que combata a propagação da degradação ecológica de viés econômico, haja vista que é notória a conexão entre pobreza e poluição, pois "a desigualdade ambiental é sem dúvida uma das expressões da desigualdade social que marcou a história do nosso país” (ACSELRAD, 2017, p. 02).

Rev. de Direito e Sustentabilidade | e-ISSN: 2525-9687 | Maranhão | v. 3 | n. 2 | p. 71 - 89 | Jul/Dez. 2017. 
Os indivíduos em situação de vulnerabilidade econômica estão mais expostos aos perigos devido à localização de suas moradias, não raras vezes, em zonas propensas a propagação de riscos nas esferas ecológicas e da saúde humana. Frente esse panorama, de desigualdade social é crível associar que existe uma "correlação entre indicadores de pobreza e a ocorrência de doenças associadas à poluição por ausência de água e esgotamento sanitário ou por lançamento de rejeitos sólidos, emissões líquidas e gasosas de origem industrial” (ACSELRAD, 2017, p. 02).

A propagação dessa desigualdade social com reflexo na seara ecológica deriva do processo de privatização do acesso aos recursos naturais essenciais para a manutenção de uma existência digna para os indivíduos. Esse processo se desenrola por meio dos direitos de propriedade intelectual, o cerceamento do acesso a esses recursos naturais que outrora eram universalizados segue a lógica economicista do mercado que tende a suprir o desperdício desses recursos através da sua privatização.

Perante o pensamento ecológico hegemônico de caráter antropocêntrico influenciado pelo sistema financeiro, é propagada a necessidade de evitar o desperdício dos recursos naturais no intuito de aplacar a problemática ecológica. Portanto, a pauta de atrelar desigualdade econômica à poluição perde força, haja vista, que o discurso adotado acerca do principal problema ambiental contemporâneo consiste no "desperdício, empresas e governos tendem, entretanto, a propugnar ações da chamada 'modernização ecológica', destinadas essencialmente a promover ganhos de eficiência e a ativar mercados" (ACSELRAD, 2017, p. 02).

Para que ocorra a materialização da justiça ambiental urge a necessidade de reformulação da atual conjectura social originária do modelo econômico neoliberal. De tal modo que o Estado tenha condições de criar políticas públicas voltadas para atuar, com foco, na diminuição da desigualdade social e por consequência minimizar o processo de degradação ecológica. Para tanto, se torna necessária a efetivação dos preceitos atinentes a materialização da justiça social, uma vez, que "as teorias modernas de justiça social exprimem essa ideia sob a forma do princípio 'maximin', segundo a qual a sociedade justa deve maximizar oportunidades e condições mínimas de vida oferecidas pelo sistema social” (PIKETTY, 2015, p. 10).

O movimento ambientalista contemporâneo combate o processo de degradação ecológica por meio da discussão sobre mecanismo que assegurem a diminuição da desigualdade social, na seara econômica, para assim tentar refrear/minimizar os danos ocasionados pela 
poluição. No entanto, o discurso ecológico hegemônico propagado pelo sistema financeiro vislumbra que parte dos atores globais dominantes compostos pelos Estados hegemônicos e empresas transnacionais não reconhecem a amarração entre injustiça social e degradação ecológica. Assim, na economia globalizada "por sua vez, os atores sociais que percebem a importância desta relação lógica, ao contrário, não confiam no mercado como instrumento de superação da desigualdade ambiental e promoção de justiça ambiental" (ACSELRAD, 2017, p. 02).

O combate à desigualdade social é fundamental a fim de minimizar/suprimir os danos ecológicos causados pela poluição, sob essa ótica é necessária uma nova acepção de justiça comprometida com a complexidade da problemática ecológica contemporânea fruto de uma sociedade de risco que está em constante processo de transformação. Dessa forma, se faz imperativo o rompimento com a abordagem jurídica tradicional na esfera ecológica, pois a pluralidade da matriz epistemológica de justiça ambiental oriunda de uma nova lógica epistemológica forjada na complexidade é essencial para enfrentar o processo de degradação ecológica moderna.

A concepção um novo modelo de justiça ambiental, necessita estar comprometida com a superação do discurso ambiental hegemônico e se voltar ao combate à desigualdade social, de viés econômico, no intuito de buscar alternativas para solucionar os problemas ecológicos contemporâneos, como a poluição ligada aos indivíduos em situação de vulnerabilidade econômica. Para tanto, é necessário asseverar a construção de mecanismos de participação democrática para os grupos sociais que são afetados pelos impactos oriundos do cerceamento de acesso aos recursos naturais. Assim, estes grupos sociais teriam a capacidade de participar de todas as etapas decisórias do acesso/manutenção dos recursos naturais pertencentes aos seus respectivos territórios com o intuito de materializar uma existência digna.

\section{CONSIDERAÇÕES FINAIS}

O artigo teve a premissa de realizar um diagnóstico sobre a degradação ecológica na contemporaneidade. O processo de globalização da economia, da revolução informacional e o déficit democrático por meio da atuação do mercado corroboram no estabelecimento de uma sociedade de risco. Diante desse cenário global/local o risco ambiental é distribuído de forma desigual entre os indivíduos, e afeta com impacto mais contundente os grupos sociais historicamente vulnerabiliuzados localizados em sociedades ditas periféricas.

Rev. de Direito e Sustentabilidade | e-ISSN: 2525-9687 | Maranhão | v. 3 | n. 2 | p. 71 - 89 | Jul/Dez. 2017. 
Nesse contexto, a sociedade moderna sofre com o choque de inúmeros processos sociais complexos oriundos da ação da globalização e acaba por incorporar o risco a condição humana moderna. Sob essa premissa, a distribuição desigual do risco ambiental entre os indivíduos acaba por afetar de forma mais contundente os extratos sociais dos grupos historicamente vulnerabilizados, dentre os quais estão inclusos: as populações negras, os indígenas, os pobres e os trabalhadores.

O fenômeno da repartição desigual do risco ecológico aumenta de forma exponencial as condições de precarização da vida, em especial, dos indivíduos pertencentes aos grupos historicamente vulnerabilizados. A divisão desigual do risco ecológico está condicionada a certos fatores que compõe o alicerce da estrutura social moderna, dentre os quais se destaca, o poder econômico dos indivíduos. A construção deste cenário contribui na formação/consolidação de uma sociedade desigual devido a sua estruturação economicista, que prolata a desigualdade ecológica entre os indivíduos, haja vista, que o desenvolvimento econômico não ocorre de maneira uniforme.

Nesse cenário, a incorporação de novas tecnologias auxilia na integração/conexão de um novo contex to social. Sob essa conjectura, o acesso a informação acerca do grau de toxidade dos bens/insumos desenvolvidos passa a ser controlado/massificado pelas empresas transnacionais privadas através de suas redes de produção, essas informações agora não estão acessíveis a todos os indivíduos. A política se tornou o palco onde o risco atua, pois os problemas conectados a fabricação do risco na sociedade moderna são largamente divulgadas/debatidas a partir de ponto de vista "democrático", mas as decisões são tomadas a portas fechadas.

As demandas por justiça ambiental na contemporaneidade operam a partir dos impactos gerados pela desigualdade econômica, haja vista, que estes impactos se irradiam e tem como efeito colateral o alastramento da desigualdade ambiental em sociedades ditas periféricas. Para tentar reverter esse prognóstico, é imperativo (re)pensar a compreensão de justiça, sob o viés ambiental com o objetivo de gerar uma mudança no atual padrão ecológico hegemônico.

A concepção de uma sociedade que combata a desigualdade social deve ser direcionada por um padrão de justiça complexo fundado num sistema de colaboração que atenda os interesses mútuos dos indivíduos. A formulação destes conceitos irá gerar alterações substanciais na concepção de justiça e reverbera na edificação de um padrão de justiça ambiental esboçado pelo movimento ambientalista contemporâneo. 
O conceito de justiça ambiental tem por característica a aplicação de um tratamento justo por meio da inclusão equitativa dos grupos sociais afetados diretamente pelos problemas ecológicos. O movimento ambiental prolata essa nova acepção de justiça, que está balizada na luta contra a desigualdade social na seara econômica. Os indivíduos em situação de vulnerabilidade econômica são mais expostos aos perigos, não raras vezes, devido à localização de suas moradias em áreas predispostas a propagação de riscos que afetam as esferas ecológicas e da saúde humana.

Para a concretização da justiça ambiental é necessária a reformulação da atual conjectura social procedente do arquétipo econômico neoliberal. O movimento ambientalista contemporâneo luta contra a ação da degradação ecológica através do (em)debate sobre a criação de mecanismos que assegurem a diminuição da desigualdade social de viés econômico para dessa forma tentar refrear/minimizar os danos ocasionados pela poluição oriunda da pobreza.

A luta contra a desigualdade social é fundamental a fim de minimizar/suprimir os danos ecológicos causados pela poluição procedente do processo de precarização da condição de vida dos sujeitos. A participação democrática também figura como condição essencial para reverter esse quadro. A construção de mecanismo mecanismos de participação democrática junto as comunidades afetadas pelo uso de seus recursos naturais. Assim, os indivíduos teriam condições de participar em todas as etapas decisórias que envolvam a deliberação sobre o acesso/manutenção dos recursos naturais pertencentes aos seus respectivos territórios.

O combate as discrepâncias de ordem econômica contribuiria na construção de alternativas para contornar os problemas ecológicos contemporâneos. Sob essa ótica, urge a necessidade de uma nova acepção de justiça que tenha como premissa o combate à desigualdade social de viés econômico. Os preceitos assertivos da justiça ambiental tem a capacidade de abarcar a complexidade da problemática ecológica contemporânea no intuito de contribuir para a combate a distribuição desigual do risco ecológico em sociedades ditas periféricas. 


\section{REFERÊNCIAS}

ACSELRAD, Henri. JUSTIÇA AMBIENTAL - novas articulações entre meio ambiente e democracia. Disponível em:

<http://www.justicaambiental.org.br/projetos/clientes/noar/noar/UserFiles/17/File/JANovasAr ticulacoes-\%20ms.pdf >. Acesso em: 02 Jul. 2017.

ACSELRAD, Henri; MELLO, Cecília Campello do Amaral; BEZERRA, Gustavo das Neves. O que é Justiça Ambiental?. Rio de Janeiro: Garamond, 2009.

ARENDT, Hannah. A condição humana. 10.ed. Rio de Janeiro: Forense Universitária, 2007.

BAUMAN, Zygmunt. O mal-estar da pós-modernidade. Rio de Janeiro: Jorge Zahar Editora, 1998.

BECK, Ulrich. Sociedade de risco: rumo a uma outra modernidade. São Paulo: Editora 34, 2011.

CASTEL, Robert. As armadilhas da exclusão. In: BOGUS, Lucia. Desigualdade e a questão social. São Paulo: EDUC, 2000.

CASTELLS, Manuel. A sociedade de rede - a era da informação: economia, sociedade e consumo. 6.ed. São Paulo: Paz e Terra, 2006.

FROTA, Henrique Botelho Frota; MEIRELES, Antônio Jeovah de Andrade. A justiça ambiental como paradigma para as políticas de desenvolvimento urbano no Brasil. Disponível em: <http://www.conpedi.org.br/manaus/arquivos/anais/brasilia/02_862.pdf >. Acesso em: 02 Jul. 2017.

FOUCAULT, Michel. Nascimento da Biopolítica. Curso dado no Collège de France (19781979). São Paulo: Martins Fontes, 2008.

GIDDENS, Anthony. Mundo em descontrole. 3.ed. Rio de Janeiro: Record, 2007

KELSEN, Hans. Teoria Pura do Direito. 2.ed. Tradução João Baptista Machado. São Paulo: Martins Fontes, 1998.

LEFF, Enrique. Saber ambiental: sustentabilidade, racionalidade, complexidade, poder. 11.ed. Petrópolis: Vozes, 2015.

MÉSZÁROS, István. O poder da ideologia. São Paulo: Boitempo, 2004.

PIKETTY, Thomas. A economia da desigualdade. Rio de Janeiro: Intrínseca, 2015.

RAWLS, John. Uma Teoria de Justiça. 2.ed. Martins Fontes, 2002.

SANTOS, Laymert Garcia dos. Politizar as novas tecnologias: o impacto sociotécnico da informação digital e genética. São Paulo: Editora 34, 2011. 
SMITH, Adam. The Theory of Moral Sentiments. 6.ed. São Paulo: Metalibri, 2006.

TYBUSCH, Jerônimo Siqueira. Sustentabilidade Multidimensional: Elementos Reflexivos na produção da Técnica Jurídico-Ambiental. Tese de Doutorado - Universidade Federal de Santa Catarina, 2012.

TYBUSCH, Jerônimo Siqueira; AGNE TYBUSCH, Francielle Benini. Ecologia Política, Redes Colaborativas e Justiça Ambiental no Brasil. In: Direito \& Novas Mídias. OLIVEIRA, Rafael dos Santos; SILVA, Rosane Leal da. (Orgs). Curitiba: Íthala, 2015. 